\title{
3. Playing an Automated World
}

\author{
Miguel Sicart
}

\begin{abstract}
In these days of technological revolution, we have two parallel trendsautomation and gamification/playful design — driving the ways we design technologies for consumption. In fact, play design has been heralded as the approach that will make the computer-mediated forms of work into pleasurable experiences. However, this very assumption is troublesome if we question what we mean by play. In this piece, I will question the assumption that making something feel like play needs to be questioned, that it has some ethical implications that need to be reflected upon, and that even though the assumption might be correct, it is so only if we properly define what we want from playing everything.
\end{abstract}

Keywords: playful design; ethical implications; playful apps; playful persuasion

\section{Introduction}

I can't remember the last time I visited a bank to transfer money. I also can't remember the last time I used an ATM to check my account. I can't recall when I last used my laptop for any banking activity. I can't remember when I last spoke to a taxi dispatcher, and I haven't communicated once with my children's school in person when they're sick.

All these mundane activities have been mediated through apps. This is a 'comfortable' new world in which my interactions with the human beings that mediate services are limited to those cases of catastrophic failures of software systems. The systems I interact with are convenient and are designed to be pleasant, engaging, and playful.

When I describe these systems as playful, I'm referring to a particular quality of their design, a set affordance that is aesthetic-driven that

Hera, T. Dela, J. Jansz, J. Raessens, B. Schouten, Persuasive Gaming in Context. Amsterdam: Amsterdam University Press, 2021 DOI 10.5117/9789463728805_CHO3 
allows users to use these services not just as functional devices but also as pleasurable experiences. In Play Matters (2014), I defined playfulness as an attitude toward the world that brings the benefits of play (expressiveness, appropriation) to activities that are, in fact, not play. Playful services want to feel like playthings, even if they are ultimately serving another purpose.

One recent example of this approach is IKEA Place, an app developed by the Swedish furniture giant that uses augmented reality (AR) to allow users to place furniture from their catalogue in a 'real space'. Users can select the furniture they are interested in and see how it would fit in a space thanks to an AR representation in the camera feed of their mobile phones. IKEA Place is far from being a game; it's a sales instrument designed to streamline the experience of the IKEA catalogue and to make a visit to the shop more efficient or even redundant. Yet the placement of objects in space feels very playful.

In this chapter, I want to critically examine playful design-services apps. I want to question why these are designed to be experienced from a playful, engaging perspective and what social, political, and ethical consequences this has for playable mundane software in different speculative playable futures. I want to explore the idea that this engaging, mundane, comfortable software might be eroding forms of labor and social connection and is doing so by applying methods and concepts from games and toy designs. The chapter addresses the following questions: What happens when services become apps? What happens when these service apps are designed as playful experiences? And what sociopolitical and ethical effects might a playable automated future have?

The chapter addresses issues of gamification and the playful design of service apps from the perspective of the philosophy of technology. To do this, post-phenomenology and the philosophy of information provide the conceptual background that allows me to frame the analysis of these applications from a critical perspective. I will also engage critically with design research, play theory, and game studies. Finally, I will try my hand at a more speculative form of research, imagining possible playable futures that illustrate the role that play might have in shaping how technologies mediate the world. My goal is to conduct an analysis of future dystopias or utopias so that we can ask questions of our technologies, practices, and ideologies before we reach a point at which we have no opportunity to do so. I don't claim to be right or to hold an empirically proven truth. I simply maintain that we need to think things through and to ask questions before we fully embrace the pains and pleasures of playable automated services. 
The chapter is divided into five sections, including this introduction. Section two presents the concept of 'soft automation', which I'll use to connect software-based (self-)services with the broader phenomenon of automation. Section three introduces the problems that arise when using play as an interface to 'soft automated' services. The section will focus on how play's capacity to create order as well as redefining action through formal rules might be a problematic design approach. Section four presents the dystopian summary of a future dominated by playable self-services; using a variation of speculative design thinking, I will present what a future of playable services might look like.

This chapter is an exploration, a probe launched toward the incoming present and the potential futures of play and playable technologies. The point of this chapter is to ask questions, to reflect, to think aloud why we need to think carefully about using play to engage people with automated self-services. This chapter wants to draw a picture of the kind of research that we need to address these issues; the kind of work that's ahead of us.

\section{Soft automation}

It's fashionable these days to be worried about automation (Vallor, 2014). Ranging from concerns about disappearing jobs (Srnicek \& Williams, 2015) to the fear of an AI planet (Bostrom, 2016), we're witnessing a revolution in the way labor is organized and eliminated. And we should be afraid of the quotidian, mundane forms of automation that we're silently allowing to take hold of our daily life.

There is a subtle, insidious, and unexpected form of automation that's changing the way we interact with services. The explosion of AI techniques for natural language processing and image recognition and the ubiquitous presence of smartphones have changed how we interact with services. Through concepts like 'big data', states and corporations alike are finding solutions to make their services more accessible to users by developing software that can be installed on a smartphone, is available $24 / 7 / 365$, and allows users to benefit from engaging with these services when they please.

This has led to a transformation of the service sector toward a self-service sector, in which service providers are increasingly software companies with some customer-facing operations, yet are focused on providing digital access to their services through software applications. As I mentioned in the introduction, banks have led the way in transforming their services into apps. In countries like Denmark, most citizen services can be accessed 
online or via apps, and this trend is extending to all interactions with all services, from the police to the nursery.

From a user perspective, there's much to like in this revolution: there are no queues; we don't need to schedule our lives around opening hours; and the simplicity of an app just makes ordinary transactions fee/ less complicated. Everything is just more comfortable. Yet, like with all comforts, there might be a trade-off that we aren't considering, one that has important implications.

The transition to self-services involves a displacement of labor from specialist workers with privileged access to the inner workings of services to users being deputized to perform service operations with the aid of software. Professions that used to be the stalwarts of the middle class and didn't require a long, academic education, like bank teller or clerk, are disappearing as we users accept doing that work ourselves, without any intermediaries. The promise of these vanishing intermediaries hides the threat of eliminating those service specialists—-such as travel agents-who understood how complex systems operated and could navigate them for us.

I call the transformation of services into self-services via software applications 'soft automation'. Soft because it's based on software, and soft because it doesn't bring forth the fears of the terminator that will kill us or the car-assembling robot that will steal our jobs. What's more, because these software-based services depend on algorithms to translate complex systems into a user-friendly interface, soft automation has the effect of displacing labor from specialist workers to users.

Why should we care about soft automation in a book dedicated to persuasive play and games? Research into games as engagement tools has shown that they can be used to increase satisfaction, engagement, and learning in users (Fuchs, Fizek, Ruffino \& Schrape, 2014; Walz \& Deterding, 2015). There are indications that some forms of gamification and game-based learning increase engagement and improve education results. If we know that games and playable interactions are engaging, what better framework do we have with which to create applications that interface complex systems to users in appealing ways?

Habitica (HbitRPG, 2013) is a classic example of a take on gamification. On their GitHub page, the developers of this project define it as an 'open source habit building program which treats your life like a Role Playing Game' (HabitRPG, 2018). Habitica is essentially a to-do-list application that uses mimicry and make-believe to engage users in keeping track of their habits and potentially changing them. Habitica uses the conventions of computer role playing games to generate this effect: players create a character that levels up and acquires new items as tasks are fulfilled, from going to the gym to taking out the trash. 
Using a game structure derived from role-playing games as a motivational instrument is a very clever design tool: role-playing games are based around the fulfillment of tasks, and personal development can be framed as a way of leveling up. The application of the design and aesthetic language of games makes Habitica an example of classic gamification, namely the application of game structures to activities with the goal of making them pleasurable.

Gamification could be applied to making soft automation processes more engaging by making them playful. It wouldn't be surprising to see game designers and service providers collaborate in the development of pointbased systems that would help users to transition from using services to self-service experiences. But if (or when) this happens, we'll need to question the consequences of framing self-services as playable experiences that use the design vocabularies of games and playthings. These are questions that will have an impact on the way we experience technology as well as in the role of gamification design, serious games, and play design in the future.

\section{Playing services}

Play is a powerful instrument to engage users of digital systems, make them more attached and engaged to their activities, and translate repetitive, boring, and mildly complex tasks into something more pleasurable (Bogost, 2007). The promise of play is that by making things feel like games, and by structuring the activity using game-design techniques, users can play the world and therefore feel more engaged with the activity at hand (Deterding, 2012).

This approach, while controversial (Lieberoth, 2015), has been shown to be somewhat effective (Márquez Segura et al., 2016), but there's a trade-off that I believe we haven't properly discussed yet. Let's go back to classic play theory and read the work of Huizinga ([1938] 1992) and his successors (Henricks, 2016) from the perspective of a culture that wants to have play everywhere.

Huizinga characterized play by describing it as a separate, autotelic activity that imposes order in the world. It's not my intention to discuss here the concept of the magic circle again (Consalvo, 2009). My focus is Huizinga's argument that play is a voluntary activity that takes place in bounded space and time, that has a purpose of its own, and that is separate from the real world. Whatever happens in play is a consequence of the activity itself, and what motivates us to engage with this activity is derived from the pleasures that we can experience when playing. 
When we play a game, for example, its rules help us impose an order to our activity. We play in turns, we know who can win and who can lose, and we have a limited yet meaningful set of actions we can take in order to interact with the game and other players. Of course, things aren't as clear-cut as this description suggests. Goffmanian research on games and play (Goffman, 1961) shows how play is also a social event that requires from players their active participation in maintaining social relations that are both intrinsic to the play activity and related to the social relations of players outside the game (Deterding, 2017).

Huizinga provided a set of concepts to describe and define play, and contemporary play scholars like me are still dealing with them. We've extended Huizinga's core notions of play by addressing the permeability of the magic circle, the relationship between play and games (Malaby, 2007), or the phenomenon of 'bleed' in live action role-playing games (Waern, 2011). And yet, we're still discussing play and games through the concepts presented in Huizinga's Homo Ludens. I don't mean to downplay the importance of these concepts, nor do I want to propose an alternative; instead, I want to highlight that the way we analyze and design play is deeply rooted in issues of separateness, the autotelic purpose of play, and its imposition of order in the world.

Furthermore, despite efforts to describe the morality of games and play (Sicart, 2009), we still need to properly address how an autotelic activity can have an effect in our moral lives. Huizinga famously declared that play is beyond morality, and Caillois and other researchers questioned the ontological status of play once the 'real world' starts having an effect on its structures (Caillois, 2001). Similarly, Goffman pointed out how part of the social act of playing is negotiating what elements external to the activity of playing the game have an influence on playing the game and why these externalities might have catastrophic consequences for the activity of play (Goffman, 1961).

If we want to address the challenges that gamification and persuasive games face in their attempt to make play a more engaging way of interacting with services, it's essential to discuss the ontological processes that happen at play and how they shape the experiences of players/users. Huizinga's description of play, so influential in our culture, provides players with the argument that their actions when playing are solely motivated by their intention to play to experience the pleasures of play itself. The autotelic, separate nature of play, even if qualified through concepts like bleed (Waern, 2011), still justifies the 'it's just a game' argument, i.e., the co-optation of responsibility for the actions taken during play, because play is a separate activity with its own logic and purpose. 
It's precisely this argument that I find to be the most dangerous, unexplored domain when it comes to a playable future. Any plaything, from games to toys to playgrounds, is a technology designed to mediate human experience and to help structure and engage with the order that play requires to become an activity. In other words, playthings shape human experience toward the activity of play. When we apply elements of game or play design outside the domain of games, we're trying to replicate the way playthings mediate human experience. Therefore, we need to understand that process of shaping experience. To do this, I will turn now to post-phenomenology.

Post-phenomenology, a contemporary phenomenological school (Ihde, 2012), has developed a methodological approach that allows for identifying and questioning the role that a particular technology has in the experience of the world (Verbeek, 2008; Aagard, 2017). The experience of the world is always mediated by technology, shaping intentionality and helping construct subjectivities (Rosenberger, 2014). This is a world-construction process: Our experience is that of creating and being in a world in which our experience and our subjectivity become. Games are devices explicitly designed to construct that world by constraining agency and creating obstacles that focus our experience.

Much like games, computers have the capacity to organize our experience based on rules. This limits our action but also enhances it, giving it new potential meaning: running away from zombies, becoming healthier one run at a time. Computational technologies perform an operation in our experience that modifies our experience of the world: computers create worlds, much like play.

As an example, the data tracked by sensors on phones is used by fitness trackers to visualize and present that data using digital maps and graphical representations of movement, speed, and distances. Computer-mediated exercise is an activity that takes place in a computed world. Bodies and motions become those bodies and motions that can be tracked and located in the digital world of the fitness tracker.

Post-phenomenology allows us to see how computing technologies and play arrange our experience in similar ways. The technologies of play and computation not only mediate but also give sense, purpose, and meaning to the experience of the world. But this doesn't explain the risks of the 'it's just a game' argument. To fully explain my concerns, I want to examine what play and its technologies do to the world.

The relationship between computers and play can be described as a process of re-ontologization (Floridi, 2013). Information and communication technologies like smartphones and computers are re-ontologizing 
technologies that transform the nature of the world as experienced precisely because they are information machines: 'the ontology of the information technologies available [...] is the same as (and hence fully compatible with) the ontology of their objects, the raw data being manipulated' (ibid, p. 7). Re-ontologization is the 'source of some of the most profound transformations and challenging problems that we will experience in the close future, as far as technology is concerned' (ibid, pp. 6-7).

What makes computing machines catalyzers of this re-ontologization process is 'the fundamental convergence between digital resources and digital tools. The ontology of the information technologies available [...] is now the same (and hence fully compatible with) the ontology of their objects [...] in the re-ontologized info sphere, there is no longer any substantial difference between the processor and the processed, so the digital deals effortlessly and seamlessly with the digital' (ibid). Computers turn the informational world into a digital environment, and they also afford particular interactions, effectively re-shaping the nature of the world.

Play is also a way of re-ontologizing the world. Playing a game is creating and inhabiting a world, a process of rearranging things and agency so that new relationships, behaviors, and experiences can take place. Videogames give us worlds, from World of Warcraft's Azeroth to Fallout's The Wasteland. Games also give us the communal village of fear and monsters of Werewolf, or the world-about-to-die of Pandemic. Sports give us the contained worlds of stadiums and courts, with their own logic and ethics. Play is a way of creating worlds within this world.

Play is a re-ontologizing activity because it has three characteristics that allow it to re-shape the essence of the world. First, play is appropriative: to play is to take over a situation, a context, a space, and a time and make it the scene or the instrument of play. This act of appropriation is always contextual and open to negotiation: we don't take over the whole of an object or the whole of a situation but only those aspects that we find interesting, relevant, or appropriate for our goals within the activity of playing.

Second, play is autotelic. The purpose of the activity of appropriating the world is always negotiated, expressed, and applied to the situation or object play that takes over. When that purpose is fulfilled, the activity ends. To play is to play for a purpose, which is sometimes fun but sometimes is not. Play has a purpose of its own, a purpose that is explicit, argued for, and is not rigidly determined.

Finally, play is expressive. To play is not to consume or perform actions in a particular order for particular goals; to play is to produce or to perform actions in a particular order with a personal touch, for a personal reason, 
a reason that becomes expression. To play is to make a world in which that being is possible, meaningful, and creative (Sicart, 2014).

Play redefines the nature of the world and radically changes it. It reontologizes the world in more temporary, negotiated, and impermanent ways than computers but still in ways that are creatively, ethically, and politically relevant. To play is to appropriate the world to create $a$ world in which we can play and in which the activity we are engaged with is meaningful and we can express ourselves. These are impermanent worlds that have an impact but not permanence beyond the activity of play.

The computational capacity of re-ontologization is at the heart of soft automation: Software helps us to redefine tasks that require expertise and turn them into self-services in which computational agents are specifically designed to help users achieve their goals. These services are re-ontologized, their nature changed so computational systems can have degrees of agency that aid users in performing tasks.

These transformations need to be shaped in such a way that users find them palatable. Playful design, through gamification practices, helps users leverage these new computational-driven experiences. By turning the rules and algorithms that computers use to re-ontologize the world into game-like rules and playable instructions, playful design makes the experience of a computationally re-ontologized world more accessible and more interesting.

A good example of this process is Siri, Apple's voice-controlled assistant. I have in the past written about Siri as a plaything (Sicart, 2014). However, it's a critical example to return to because it illustrates how play and computation are related and how playfulness can be used to interface with a computational world. Siri is the result of an assemblage of technologies and practices, from voice recognition to cloud computing, that allows us to interact with our mobile phone just using our voice. Siri is the affable voice of a computable world.

And that's why it's so important that Siri has been designed with humor and playfulness as part of its repertoire of answers. Siri is not just a functional interface; it's a playful interface that has opinions. It can reply with limited but charming wit and seems to be willing to listening to us when nobody else wants to. A playful Siri implies an engagement with the computationally re-ontologized world that is in itself playful. It's not just an interface; it's Siri, with its quirks and opinions. It's a joyful interface, re-ontologizing through play the functions of the interface so that engagement with that computational environment is more palatable.

When we make self-services playful, when we create the activity of play, we are reconstructing a world that orients our experience based on the 
autotelic goals and actions afforded by the technologies themselves. In the next section, I will explore some possible playable futures that might be the outcome of the playful re-ontologization of computational self-services.

\section{Playable futures}

I now want to speculate about the playable, soft-automated futures that await us, in order to trace a potential future of playable technologies from the perspectives of play and automation (Frase, 2016). These potential futures could allow us to understand the potential impact of a playable future and reflect upon what a positive playable future would be like. This is a speculative design-thought experiment, with the goal being to consider models of a future in which playful soft automation has succeeded.

First, imagine that soft automation has succeeded in eliminating all intermediary jobs. In order to engage with any service, from ordering food to applying for a new passport or naming a child, people just need the right app on their phone or browser. People seldom need to interact with another person-even healthcare has been automated. The bureaucrats are all behind the curtains of highly automated systems, dealing exclusively with exceptions and malfunctions. They are the elite, shaping the way automation works and the way we experience it. They are the human gatekeepers of the algorithms. But they are as remote and arcane as the algorithms themselves.

Once all services are automated, we need to make them not just Normanfunctional, not just devices designed with Norman's usability principles in mind (Norman, 2002), but also engaging. Usability and practical concerns are not enough for people to change their habits. We need emotional design so that we find pleasure in performing these tasks through apps. This leads to a great play awareness moment: If only we can make things feel like play, people will have better lives and be more engaged in their activities. Work applications, tasks, chores; they can all be experienced as we experience toys, namely as instruments that extend our agency on the world, that give us not just increased engagement but also a feeling of appropriation of the world, of being able to self-determine the purpose of our actions.

We can imagine a future of playable services that are good to experience, that are fun and pleasurable and act like games or toys. The goals of these pleasurable services are to serve and entertain. We already have examples of this kind of service, such as Carrot's animistic designs for mobile apps (http://www.meetcarrot.com). Carrot apps are based on the idea of giving a voice to the processes and activities that the user engages with when using 
those apps. Whether it's checking their to-do lists or taking exercise, there's a character that ruthlessly comments on the users' efforts.

Carrot's application of animistic design is fundamentally playful: by creating a character with a personality that comments on player actions, Carrot designers establish an experiential relation of alterity between the user and the technology (Verbeek, 2006), using mimicry as a playful way of establishing that relationship (Caillois, 2001). In a future in which services have been automated into playful self-services, Carrot's strategy might be a dominant one, namely, to make these services feel and behave like toys so that all these mundane activities become more than tasks we have to complete.

In this future, playable services might engage us more, but they will also bring a certain type of focus on the experience. Playful economic transactions may hide how self-services eliminate a type of job that has often been considered part of the broad middle class. These services can be toys, but they might be the toys of affluence and ignorance, the self-serving self-services that isolate users in playgrounds that are well-defined, secure, and ultimately controlled. The playground can be a panopticon in which we voluntarily submit to ignorance just to experience the pleasures of play. A playable self-service world will hide the processes of re-ontologization through the pleasures of play, reducing our engagement with the meaning and consequences of our interactions, making us play ourselves to death (Postman [1985] 2005).

There is another potential playable future in which automated selfservices are functional, pragmatic applications that don't get in the way of our goals. In this possible future, we aren't expected to be emotionally engaged with these services; they are there, they are functional, and they facilitate our living in computational societies. What is the role of play in this automated society? If the software isn't playful but it works and there's no other option than to use it, why should we even think about play? In a future of efficiency, play can be an instrument to reclaim agency in automated worlds, a way of experiencing the world on our own terms.

Play can be a strategy to experience self-services as playthings. All these soft-automated systems require our complicity to work. Play gives us instruments to challenge them, to reclaim the importance of personal communication, of the pleasures in the mundane, of being recognized not by an algorithm but by a person who knows you. We love the convenience of self-services, yet we yearn for worlds that are more human, more local, and more personal: organic, gluten-free, locally sourced. Play might give us a way of satisfying some of that yearning. 
Take, for example, the application Converse, which is designed to translate languages using sophisticated speech recognition and cloud-computing technologies. Converse presents itself as more than just an instrument; it has a vibrant interface full of animations and audiovisual feedback that makes the act of translation feel like a way of connecting people with each other. Converse isn't a functional instrument but more a pleasurable form of engagement with automated translation services.

Similarly, the application Insight Heart uses augmented reality (AR) to allow users to see and navigate the cardiovascular system using their mobile devices as windows to a medically correct representation of the human anatomy. This is an instrument and a toy that leverages the magic of AR with the functionality of a learning application.

There are also aesthetic or political examples of this future. The mobile application Buy Partisan allows users to scan the barcode of groceries, figure out the political leanings of their producers and manufacturers, and therefore orient consumerism toward supporting political ideas. More aesthetically inclined is Die With Me, a chat application that will only allow users to communicate with others when their devices have $5 \%$ of battery or less. Instead of providing infinite access to communication, this app limits the available time to communicate, while at the same time extending the meaning of chatting on a phone, perhaps with strangers, for a painfully short time before the battery dies and with it the connection to the other person.

These are examples of currently available services. But perhaps the playable future we deserve, the one that would allow us to resist the pressures of soft automation and use playfulness as an instrument for resistance, should instead be found in the results list of the Stupid Shit No One Needs \& Terrible Ideas Hackathon (stupidhackathon.com). This is an event that produces terrible contraptions that make fun of the technologies that define our time. From analog takes on AR like Intestine AR (http://www.jhclaura. com/peep-rack/) to the brilliant Hypochondriapp (http://hypochondriapp. io), which will always provide the worst possible diagnosis for whichever symptoms are typed in, the Stupid Shit Hackathon provides a playful insight into what happens when we play with the computers around us.

Play allows us to define our goals in the experience of the world. In this playable future, we play the self-services: we poison the data needed to record our behavior by being silly; we cheat trackers or poke fun at the unavoidable creepiness of permanent behavioral tracking. Alternatively, we can even try different, new strategies based on the disorderly aspect of play. For example, we could photocopy and fax the screen of our portable 
device showing our bank statements, instead of using the convenient, yet impersonal, email systems embedded in finance applications.

This is a romantic take on play, perhaps a dated vision that evokes the more optimistic dreams of the New Games movement (DeKoven, 2013). I may be naive and think that we can use not just the capacity that play has to engage us but also the capacity that it has to define its own goals and let us have ownership of them and our expectations. In a future of self-services, where we are carefully and functionally guided to press the right buttons, play might be the way of making that world less mechanically mundane.

We are moving toward an automated future, and this might be a ludic century. The combination of both machines and play, I believe, will shape our future, and so thinking about the excesses we might incur could help us find livable middle grounds.

\section{Conclusions}

In this chapter, I wanted to raise some questions about playable futures. Serious games and gamification have provided us with the conceptual tools to apply game-design principles outside the domain of games. Self-services are an obvious target for playful redesigns, as they might leverage their functional mundanity with increased playable engagement. But play, given its autotelic nature, might actually stop us from understanding the societal and cultural impact that soft automation might have.

This chapter charts the poles between the optimism regarding playable technologies and a reflection on how play can be problematic. Play gives us new worlds, and computers give us new comforts. It's easy to be seduced by them, to be persuaded to use these playable services because they are not just services but because they engage not only with our needs but also with our wants. Yet we can't ignore the fact that these take place in the context of accelerating the capitalism that promotes the destruction of labor so that the accumulation of capital can be streamlined. By turning services into self-services, labor is displaced from employed specialists to users. By making users 'play' these services, we isolate them from the effects they might have in culture, society, and the commons. And so we are risking feeding a self-reinforcing, capitalist-optimizing machine.

Therefore, as a small and not very satisfactory conclusion, I want to insist on a basic idea: we need to think about the implications of making things other than games have a game feel. Games are instruments created to craft worlds in which player agency is extended and limited by clear 
rules, justified by pleasurable goals, and encapsulated in the voluntary logic of participating in the game. If we make services feel like play, we may be making them more pleasurable, but we may also be making them more separate, their rules and procedures to be interpreted as arbitrary limitations imposed on the world instead of social contracts that bind our actions to collective goods or personal goals. If we don't take these implications seriously, if we don't think through how a playful world may affect our engagement with society and its technologies, we're risking turning the world into a playground that hides in playable pleasures the harsh realities of capitalistic automation.

\section{References}

Aagaard, I. (2017). Introducing Postphenomenological Research: A Brief and Selective Sketch of Phenomenological Research Methods. International Journal of Qualitative Studies in Education, 6(30), 519-533. https://doi.org/10.1080/09518398.2016.1263884. Bogost, I. (2007). Persuasive Games. Cambridge, MA: MIT Press.

Bostrom, N. (2016). Superintelligence: Paths, Dangers, Strategies. Oxford: Oxford University Press.

Caillois, R. (2001). Man, Play and Games. Urbana and Chicago, IL: University of Illinois Press.

Consalvo M. (2009). There Is No Magic Circle. Games and Culture, 4(4), 408-17. https://doi.org/10.1177/1555412009343575.

DeKoven, B. (2013). The Well-Played Game. Cambridge, MA: MIT Press.

Deterding, S. (2012). Gamification: Designing for Motivation. Interactions, 19(4), 14-17. https://doi.org/10.1145/2212877.2212883.

—. (2017). Alibis for Adult Play: a Goffmanian Account of Escaping Embarrassment in Adult Play. Games and Culture, 3(3), 260-279. https://doi. org/10.1177/1555412017721086.

Floridi, L. (2014). The Fourth Revolution. Oxford: Oxford University Press.

- (2015). The Ethics of Information. Oxford: Oxford University Press.

Frase, P. (2016). Four Futures: Life After Capitalism. London: Verso.

Fuchs, M., Fizek, M., Ruffino, P. \& Schrape, N. (2016). Rethinking Gamification. Lüneburg: Meson Press.

Goffman, E. (1961). Encounters. Two Studies in the Sociology of Interaction. Indianapolis, IN: Bobbs-Merrill.

HabitRPG (2013). Habitica [Mobile App].

- — (2018). Habitica. Retrieved 24 September 2018 from https:/github.com/ HabitRPG/habitica. Accessed 1/3/2018. 
Henricks, T.S. (2016). Play and the Human Condition. Urbana and Chicago, IL: University of Illinois Press.

Huizinga, J. (1971). Homo Ludens. London: Beacon Press.

Ihde, D. (2012). Experimental Phenomenology. SecondEdition. New York, NY: SUNY Press. Lieberoth, A. (2015). Shallow Gamification. Games and Culture, 1o(3), 229-248. https://doi.org/10.1177/1555412014559978.

Malaby, T.M. (2007). Beyond Play: A New Approach to Games. Games \& Culture, 2(2) (2007), 95-113. https://doi.org/10.1177/1555412007299434.

Segura, E.M., Waern, A., Segura L.M., \& Recio, D.L. (2016). Playification. In CHI PLAY '76: Proceedings of the 2016 Annual Symposium on Computer-Human Interaction in Play. New York, NY: ACM Pres, 376-88. https://doi.org/10.1145/2967934.2968099.

Postman, N. (2005), Amusing Ourselves to Death:Public Discourse in the Age of Show Business. London: Penguin Books.

Rosenberger, R. (2014). Multistability and the Agency of Mundane Artifacts: From Speed Bumps to Subway Benches. Human Studies, 37(3), 369-92. https://doi. org/10.1007/s10746-014-9317-1.

Sicart, M. (2009). The Ethics of Computer Games. Cambridge, MA: MIT Press. . (2014). Play Matters. Cambridge, MA: MIT Press.

Srnicek, N., \& Williams, A. (2015). Inventing the Future. London: Verso.

Vallor, S. (2014). Moral Deskilling and Upskilling in a New Machine Age: Reflections on the Ambiguous Future of Character. Philosophy \& Technology, 28(1), 107-24. https://doi.org/10.1007/s13347-014-0156-9.

Verbeek, P.P. (2006). What Things Do. University Park, PA: Penn State University Press.

- (2008). Cyborg Intentionality: Rethinking the Phenomenology of Humantechnology Relations. Phenomenology and the Cognitive Sciences, 7(3), 387-95. https://doi.org/10.1007/s11097-008-9099-x.

Waern, A. (2011). “I'm in Love with Someone That Doesn't Exist!” Bleed in the Context of a Computer Game. Journal of Gaming \& Virtual Worlds, 3(3), 239-57. https://doi.org/10.1386/jgvw.3.3.239_1.

Walz, S.P. \& Deterding S. (2015) (eds.). The Gameful World. Cambridge, MA: MIT Press.

\section{About the author}

Miguel Sicart is Associate Professor at the Center for Computer Game Research at IT University Copenhagen. He is a play scholar with a background in philosophy of technology, literature, and game studies. Sicart is the author of Play Matters (2014), Beyond Choices: The Design of Ethical Gameplay (2013), and The Ethics of Computer Games (2009), all published by the MIT Press. 
